\title{
Relational dynamics amongst personal resources: Consequences for employee engagement
}

\begin{tabular}{|c|c|}
\hline \multicolumn{2}{|c|}{$\begin{array}{l}\text { Authors: } \\
\text { Nicola Vermooten }{ }^{1} \text { (D) } \\
\text { Johan Malan }{ }^{1} \text { (D) } \\
\text { Martin Kidd }{ }^{2} \text { (D) } \\
\text { Billy Boonazier }{ }^{1} \text { (D) }\end{array}$} \\
\hline \multicolumn{2}{|c|}{$\begin{array}{l}\text { Affiliations: } \\
{ }^{1} \text { Department of Industrial } \\
\text { Psychology, Faculty of } \\
\text { Economic and Business } \\
\text { Management Sciences, } \\
\text { Stellenbosch University, } \\
\text { Stellenbosch, South Africa }\end{array}$} \\
\hline \multicolumn{2}{|c|}{$\begin{array}{l}{ }^{2} \text { Centre for Statistical } \\
\text { Consultation, Faculty of } \\
\text { Economic and Business } \\
\text { Management Sciences, } \\
\text { Stellenbosch University, } \\
\text { Stellenbosch, South Africa }\end{array}$} \\
\hline \multicolumn{2}{|c|}{$\begin{array}{l}\text { Corresponding author: } \\
\text { Nicola Vermooten, } \\
\text { nicolavanderwest@gmail.com }\end{array}$} \\
\hline \multicolumn{2}{|c|}{$\begin{array}{l}\text { Dates: } \\
\text { Received: } 29 \text { Dec. } 2019 \\
\text { Accepted: } 01 \text { Dec. } 2020 \\
\text { Published: } 16 \text { Feb. } 2021\end{array}$} \\
\hline \multicolumn{2}{|c|}{$\begin{array}{l}\text { How to cite this article: } \\
\text { Vermooten, N., Malan, J., } \\
\text { Kidd, M., \& Boonazier, B. } \\
\text { (2021). Relational dynamics } \\
\text { amongst personal resources: } \\
\text { Consequences for employee } \\
\text { engagement. SA Journal of } \\
\text { Human Resource } \\
\text { Management/SA Tydskrif vir } \\
\text { Menslikehulpbronbestuur, } \\
\text { 19(0), a1310. https://doi. } \\
\text { org/10.4102/sajhrm. } \\
\text { v19i0.1310 }\end{array}$} \\
\hline \multicolumn{2}{|c|}{$\begin{array}{l}\text { Copyright: } \\
\text { (C) 2021. The Authors } \\
\text { Licensee: AOSIS. This } \\
\text { is licensed under the } \\
\text { Creative Commons } \\
\text { Attribution License. }\end{array}$} \\
\hline \multicolumn{2}{|l|}{ Read online: } \\
\hline 回的回 & $\begin{array}{l}\text { Scan this QR } \\
\text { code with your } \\
\text { smart phone or } \\
\text { mobile device } \\
\text { to read online. }\end{array}$ \\
\hline
\end{tabular}

Orientation: Consistent with the central tenets of the job demands-resources theory, research has shown that personal resources foster employee engagement. There is, however, a gap in the literature, as limited research has explored the relational dynamics amongst personal resources.

Research purpose: Firstly, to explore the relational dynamics amongst personal resources and, secondly, to determine its consequences for employee engagement.

The motivation of the study: Employees possess multiple personal resources. In consideration of this, the researchers propose that it is necessary to adopt a structural model to capture the interrelatedness of the personal resources phenomenon and its consequences for employee engagement.

Research approach/design and method: A quantitative cross-sectional survey design was used in the study to collect primary data amongst teachers from public schools located across the Western Cape province $(n=353)$.

Main findings: The results of the study demonstrated that personal resources are related to each other and, in turn, foster employee engagement.

Practical/managerial implications: The researchers recommend human resource interventions that can be developed and implemented to cultivate personal resources, specifically emotional intelligence, work locus of control, psychological capital and calling orientation.

Contribution/value-add: A structural model was adopted to explore the relational dynamics amongst personal resources. This enabled the researchers to capture the complexity of the personal resources phenomenon and its consequences for employee engagement.

Keywords: employee engagement; emotional intelligence; work locus of control; psychological capital; calling orientation; broaden-and-build theory; conservation of resources theory.

\section{Introduction}

This article forms part of a larger study overlapping with the doctoral research of the first author on the antecedents of employee engagement amongst public school teachers. The research paradigm could be described as multidirectional interactionism or more specifically as an ecological systemic paradigm (Newacheck, Rising, \& Kim, 2006), whilst the overarching research design is a mixed-methods exploratory sequential design (Creswell \& Plano Clark, 2011) that incorporates an initial qualitative phase informing subsequent quantitative phases. During the qualitative phase, a group of 37 secondary teachers from fee-paying $(n=20)$ and non-fee-paying $(n=17)$ public schools in the Cape Winelands education district were subjected to an adapted interactive qualitative analysis (IQA) (Northcutt \& McCoy, 2004) exploring key aspects influencing their job experience, how they cope with being a teacher and what the personal attributes or resources are that enable them to cope with being a teacher.

The following themes (affinities) were identified, namely employee engagement, teaching motivation, personal characteristics, coping strategies, perceived workload, school climate, student-teacher relationships and interactions, school facilities and teaching resources, parental attitudes, social context of the neighbourhood and perceived organisational justice (Vermooten, Malan, \& Boonzaier, 2020). These themes could be described in terms of five levels, namely the teacher-level (individual), school-level (microsystem), community-level (exosystem), societal-level (macrosystem) and temporal level (chronosystem) (Newacheck et al., 2006). The findings of the IQA composite uncluttered systems influence diagram (Vermooten et al., 2020) indicated that the personal characteristics of the teachers influenced their perception of the 
societal context and their teaching motivation, whilst their teaching motivation influenced their coping strategies; their coping strategies influenced their perception of their workload, which influenced their level of engagement.

In the subsequent quantitative study, a non-probability sample of 353 participants employed in 76 participating public schools in the Western Cape was subjected to a compilation of measures focused upon the evaluation of a structural model of latent variables selected on the basis of the findings of the qualitative research phase, as well as an interpretation of the extant literature (Vermooten, 2018). The emerging teacher employee engagement model was evaluated using variance-based structural equation modelling (SEM). The prominence given to the different coping skills in the teacher employee engagement model was not supported by the results. The authors hence decided to focus on the personal resource characteristics and their impact on employee engagement in an adapted structural model. This study reports on the evaluation of the adapted personal resource and employee engagement model.

A plethora of empirical evidence has shown that employee engagement is associated with various favourable individual and organisational outcomes (Bailey, Madden, Alfes, \& Fletcher, 2017; Richardsen, 2019). Bailey et al. found that employee engagement was positively associated with individual morale, task performance, extra-role performance and organisational performance. Vermooten (2018) lists job performance, productivity and profitability, and claims that engaged employees experience positive emotions are typically in better health, effectively deal with job demands and have a positive effect on customer satisfaction.

The job demands-resources (JD-R) theory offers a conceptual framework that can be used to explicate the antecedents of variance in employee engagement. It suggests that work characteristics (i.e. job demands and job resources) (Demerouti, Bakker, Nachreiner, \& Schaufeli, 2001), personal resources (Bakker \& Demerouti, 2017; Xanthopoulou, Bakker, Demerouti, \& Schaufeli, 2007) and coping strategies (i.e. job crafting and self-undermining) (Bakker \& Costa, 2014; Tims, Bakker, \& Derks, 2013) explain variance in employee engagement.

In the not so distant past, it was assumed that employers were primarily responsible for creating a work environment that would facilitate the engagement of their employees. Modern organisations, however, are increasingly pursuing human resource practices that transfer the responsibility for employee engagement to employees. In line with this, the integration of personal resources and coping strategies (i.e. job crafting and self-undermining) into the JD-R theory acknowledges that employee behaviour is a function of both the work characteristics created by the employer and by the employees themselves (Bakker \& Demerouti, 2017).

Although research has shown that employees' personal resources foster employee engagement (Bakker \& Demerouti,
2017), the authors claim that there is a gap in the literature. Limited research has explored the relational dynamics amongst personal resources. Whilst it is important to understand which personal resources foster employee engagement, it is equally important to take cognisance of the fact that employees possess multiple personal resources. By extrapolating from research conducted by Menguc, Auh, Fisher and Haddad (2013), the current authors propose that it is necessary to study the interrelatedness of the personal resources in order to capture the complexity of the personal resources phenomenon and its consequences for employee engagement. Such research may provide an insight into the way multiple personal resources influence one another and this knowledge may be utilised to foster employee engagement.

\section{Research purpose and objectives}

The purpose of this study was to explore the relational dynamics amongst personal resources and its consequences for employee engagement. More specifically, the study aimed to:

Propose and empirically test an explanatory personal resources and employee engagement structural model consisting of a number of selected personal resources.

The results of this study will allow the authors to offer recommendations with respect to the management of the engagement of public school teachers.

The researchers decided to conduct the study amongst public school teachers in the Cape Winelands education district. The mixed-methods study conducted by Vermooten (2018) highlighted the salience of personal resources within this setting, as the work characteristics (i.e. job demands and job resources) of public schools across South Africa are frequently not conducive to employee engagement. Under these circumstances, public school teachers frequently find themselves in a position where they have to take primary responsibility for their own engagement, rather than rely on larger governing bodies, such as the national and provincial departments of education.

The following section of the article will offer a review of the extant literature. Firstly, employee engagement will be defined. Following that, the JD-R theory and its conceptualisation of personal resources will be discussed.

\section{Literature review Employee engagement}

According to Schaufeli, Salanova, González-Romá and Bakker (2002, p. 74), employee engagement denotes 'a positive, fulfilling, work-related state of mind that is characterised by vigour, dedication and absorption'.

Vigour is a positive affective response to work, characterised by feelings of physical strength, emotional energy and cognitive liveliness. Dedication refers to being actively 
involved with work, whereby employees experience a sense of enthusiasm, inspiration and pride in their work. Absorption refers to a complete captivation with work, whereby employees experience an optimal state of focused attention and intrinsic enjoyment in their work. According to Schaufeli et al. (2002), employee engagement is a relatively persistent and pervasive affective-cognitive state.

\section{Job demands-resources theory}

The JD-R theory offers a framework that can be used to explicate the antecedents of variance in employee engagement in diverse occupational settings. The JD-R theory proposed that work characteristics (i.e. job demands and job resources) influence the development of job strain (i.e. job burnout) and motivation (i.e. employee engagement) through two underlying psychological processes. These processes are the health impairment process, also known as the effort-driven process, and the motivational process, also known as the motivation-driven process (Schaufeli \& Bakker, 2004). At a later stage personal resources (Xanthopoulou et al., 2007) and coping strategies (i.e. job crafting and self-undermining) (Bakker \& Costa, 2014; Tims et al., 2013) were sequentially integrated into this framework (Bakker \& Demerouti, 2017).

\section{Personal resources}

Xanthopoulou et al. (2007) proposed that personal resources (such as optimism or self-efficacy) are important determinants of employees' adaptive capability and defined them as 'aspects of the self that are generally linked to resiliency and refer to individuals' sense of their ability to control and influence their environment successfully' (Xanthopoulou et al., 2007, p. 123).

The integration of personal resources in the JD-R theory was, however, not without challenges. Based on research conducted by Schaufeli and Taris (2014), the current authors will make three critical comments regarding the epistemological status, conceptualisation and roles of personal resources within the parameters of the JD-R theory.

\section{Epistemological status of personal resources}

The JD-R theory provides limited insight into the underlying psychological role of personal resources. Hence, the researchers will draw on the broaden-and-build theory (Conway, Tugade, Catalino, \& Fredrickson, 2013) and the conservation of resources (COR) theory (Hobfoll, 1989) to explain the underlying psychological role of personal resources within the parameters of the JD-R theory.

\section{Conceptualisation of personal resources}

Xanthopoulou et al.'s (2007) conceptualisation of personal resources subsumes a limited number of person variables (i.e. optimism, organisation-based self-esteem and self-efficacy). Schaufeli and Taris (2014) claimed that this conceptualisation does not adequately reflect personal resources. The current authors endorse this notion and contend that a more comprehensive definition of personal resources is required. Lazarus's (1991) originally defined personal resources as:

$[P]$ erson variables which influence what we are able and unable to do as we seek to gratify needs, attain goals and cope with the stresses produced by demands, constraints and opportunities. (p. 71)

The current authors define personal resources in line with Lazarus's (1991) conceptualisation.

\section{Roles of personal resources}

Personal resources have been integrated into the JD-R theory as antecedents of variance in job demands and job resources, moderator variables, mediator variables and 'third variables', explaining the relationship between employees' perception of job demands and job resources and their level of engagement (Schaufeli \& Taris, 2014). Irrespective of the role played, the relationship between personal resources and employee engagement has been well established (Karatepe, Ozturk, \& Kim, 2019; Lorente, Salanova, Martínez, \& Schaufeli, 2008; Mäkikangas, Feldt, Kinnunen, \& Mauno, 2013)

In addition to the fact that researchers have not been able to agree on where personal resources fit within the parameters of the JD-R theory, limited research has explored the relational dynamics amongst personal resources. Therefore, the current authors maintain that it is necessary to study the interrelatedness of the personal resources and its consequences for employee engagement.

The focus on the interrelatedness of personal resources corresponds with Hobfoll's (1989) COR theory. The COR theory suggests that employees strive to acquire, maintain and accumulate resources. Resources generate other resources because a particular resource can be linked to or replace another resource. The linkages and interplay between resources are known as 'resource caravans' (Hobfoll, 2001, p. 343).

Against this background, four personal resources that were empirically identified in the qualitative study by Vermooten et al. (2020) amongst public school teachers in the Cape Winelands education district will be introduced here. These personal resources are emotional intelligence (EI), work locus of control, psychological capital and calling orientation. Building upon the review of the extant literature, the relational dynamics amongst EI, work locus of control, psychological capital and calling orientation and its consequences for employee engagement will be explored.

\section{Emotional intelligence}

There are two primary approaches to research regarding EI, namely the ability model and the trait model. The ability model defines EI as a group of relatively discrete mental abilities (e.g. Mayer, Salovey, \& Caruso, 2002). The trait 
model, on the other hand, defines EI as a personality trait that occupies the lower levels of the personality hierarchies (e.g. Petrides, Pita, \& Kokkinaki, 2007). The researchers decided to adopt the ability model of EI in the study. This decision was informed by research that has shown that EI can be learned and developed (e.g. Hodzic, Scharfen, Ripoll, Holling, \& Zenasni, 2018; Kozlowski, Hutchinson, Hurley, \& Browne, 2018).

The authors defined EI in accordance with Palmer, Stough, Harmer and Gignac (2009), which translates to teachers being able to perceive and understand their emotions (i.e. emotional self-awareness), effectively express their emotions (i.e. emotional expression), perceive and understand the emotions of learners, colleagues and parents (i.e. emotional awareness of others), use emotional information in decision-making (i.e. emotional reasoning), manage their emotions (i.e. emotional self-management), positively influence the emotions of others (i.e. emotional management of others) and control their own emotions (i.e. emotional self-control).

A cross-sectional study conducted by Pérez-Fuentes, Molero, Gázquez and Oropesa (2018) amongst 2126 professional nurses in Spain demonstrated that EI had a significant positive influence on employee engagement. Toyama and Mauno (2017) showed similar results amongst 489 eldercare nurses in Japan. In a similar vein, Lestari and Sawitri (2017) found that amongst special need school teachers in Indonesia, there was a positive correlation between EI and work engagement. Turner and Stough (2019) claimed that EI plays a significant role in teacher effectiveness and that it has been shown to influence the behaviour, engagement and academic performance of learners, as well as have beneficial effects for teacher well-being, job satisfaction, collegial relations and a diminished likelihood of burnout. The importance of being able to manage learner-teacher relationships in the classroom was also evident in the IQA composite uncluttered systems influence diagram (Vermooten et al., 2020).

Against the given background, EI should be seen as an important personal resource that influences the engagement of teachers. The following hypothesis can thus be formulated:

Hypothesis 1: Emotional intelligence has a significant positive influence on employee engagement.

\section{Work locus of control}

According to Rotter (1966), locus of control is a generalised expectation about the extent to which individuals exercise control over their environment. Consistent with Rotter's conceptualisation of locus of control, Lefcourt (1966) stated that it involves the extent to which individuals accept personal responsibility for the events in their lives.

Rotter (1966) highlighted the difference between an internal locus of control and an external locus of control. This distinction refers to (Rotter, 1990):

$[T]$ he degree to which persons expect that a reinforcement or an outcome of their behaviour is contingent on their own behaviour or personal characteristics versus the degree to which persons expect that the reinforcement or outcomes is a function of chance, luck or fate, is under the control of powerful others or is simply unpredictable. (p. 489)

Individuals with an internal locus of control believe that reinforcement or outcomes are dependent on their behaviour or personal characteristics. In contrast, individuals with an external locus of control believe that reinforcement or outcomes are coincidental or under the control of influential individuals.

By extrapolating from research regarding locus of control, Spector (1988) coined the concept of work locus of control, which describes the perception employees have of the relationship between their behaviour or personal characteristics and reinforcement or outcomes at work. Employees with an internal work locus of control believe reinforcement or outcomes at work are dependent on their behaviour or personal characteristics, whilst employees with an external work locus of control believe that reinforcement or outcomes at work are coincidental or under the control of influential individuals.

Three of the dimensions that are subsumed under Palmer et al.'s (2009) definition of EI refer to a sense of mastery and perceived control over emotions (i.e. emotional self-control, emotional self-management and emotional management of others). The current authors contend that it is plausible that the sense of mastery and perceived control associated with these dimensions of EI may extend to work matters. In other words, employees, who report high EI, might be more likely to regulate and control their emotions and behaviour according to situational appropriateness. This will enable them to exercise personal control over work matters and, in turn, strengthen their belief that reinforcement or outcomes at work are dependent on their behaviour or personal characteristics. This implies that EI has a significant positive influence on work locus of control.

In a study amongst social work professionals in India, Singh (2006) found that EI and locus of control were related. Singh found that social work professionals, who had a high level of EI, believed that rewards or outcomes are dependent on their behaviour or personal characteristics (i.e. internal locus of control). A cross-sectional study conducted by $\mathrm{Ng}, \mathrm{Ke}$ and Raymond (2014) amongst 242 nurses in Malaysia showed similar results. For this reason, the researchers formulated the following hypothesis:

Hypothesis 2: Emotional intelligence has a positive influence on work locus of control.

A meta-analysis conducted by Wang, Bowling and Eschleman (2010) indicated that work locus of control predicted job performance and job attitudes such as organisational commitment and global job satisfaction. In a similar vein, Myers (2014) claimed that locus of control is a necessary component of employee engagement and that it leads to higher performance, job satisfaction and successful personal and workplace relationships. The authors consequently formulated the following hypothesis: 
Hypothesis 3: Work locus of control has a positive influence on employee engagement.

\section{Psychological capital}

Luthans, Youssef and Avolio (2007) defined psychological capital as:

[A] positive psychological state of development characterised by having confidence (i.e. self-efficacy) to take on and put in the necessary effort to succeed at challenging tasks; making a positive attribution (i.e. optimism) about succeeding now and in the future; persevering towards goals and, when necessary, redirecting paths to goals (i.e. hope) to succeed and when beset by problems and adversity, sustaining and bouncing back and even beyond (i.e. resiliency) to attain success. (p. 3)

A longitudinal study conducted amongst 515 middle managers from the recruitment industry in South Africa, Shaik and Buitendach (2015) demonstrated that work locus of control is positively related to psychological capital. Shaik and Buitendach found that middle managers, who had an internal work locus of control, displayed positive psychological capital. Bulmash (2016) had gone so far as to actually equate locus of control with psychological capital. In consideration of this, the current authors propose that work locus of control has a significant positive influence on psychological capital. More specifically, employees, who have an internal work locus of control, are more likely to experience positive emotions as a result of their effective coping with negative emotional circumstances, which builds their psychological resources, such as self-efficacy, resilience, hope and optimism. The following hypothesis was thus formulated:

Hypothesis 4: Work locus of control has a significant positive influence on psychological capital.

Gong, Chen and Wang (2019) found that employees' EI has a positive predictive effect on psychological capital and job performance. Whilst Simons and Buitendag (2013) and Allesandri, Consiglio, Luthans and Borgogni (2018) confirmed the positive link between EI and engagement. The following hypotheses could therefore be formulated:

Hypothesis 5: Emotional intelligence has a positive influence on psychological capital.

Hypothesis 6: Psychological capital has a positive influence on employee engagement.

\section{Calling orientation}

Wrzesniewski, McCauley, Rozin and Schwartz's (1997) proposed that employees pursue a career for three reasons, because it is something valuable as an end in itself and serves the greater good (i.e. calling orientation), something that is done primarily to make money (i.e. job orientation), or something that is moderately fulfilling but involves a constant process of trying to get promoted (i.e. career orientation). The mixed-methods study conducted by Vermooten (2018) highlighted the salience of calling orientation amongst public school teachers in the Cape
Winelands education district. In accordance with this, the current researchers will operationalise calling orientation as a personal resource in the study.

A review of the extant literature on the interface of spirituality, religion and career development directs attention to several definitions for calling. In response to the lack of a unified, empirically testable definition of calling, Dik and Duffy (2009) proposed a definition that can be used to guide future research. Dik and Duffy (2009) described calling as:

$[A]$ transcendent summons, experienced as originating beyond the self to approach a particular life role in a manner oriented towards demonstrating or deriving a sense of purpose or meaningfulness (i.e. purposeful work) and that which holds other-oriented values and goals as primary sources of motivation (i.e. prosocial orientation). (p. 4)

The current authors contend that calling orientation has a significant positive influence on psychological capital. They explain that employees, who have a calling orientation, might be more likely to exhibit positive psychological capital, specifically self-efficacy, hope and resilience. A cross-sectional study conducted by Hirschi (2012) amongst 259 heterogeneous employees in Germany demonstrated that a positive association exists between calling orientation and occupational self-efficacy (a dimension of psychological capital). A study by Wu and Lee (2020), however, provided more specific evidence of the strong relationship between calling and psychological capital $(b=0.43, p<0.0001)$ in a sample of 164 Taiwanese nurses. The researchers, therefore, formulated the following hypothesis:

Hypothesis 7: Calling orientation has a significant positive influence on psychological capital.

A cross-sectional study conducted by Ugwu and Onyishi (2017) amongst 207 high school teachers in Nigeria demonstrated that calling orientation had a significant positive influence on employee engagement. A time-lagged survey study conducted by Xie, Xia, Xin and Zhou (2016) amongst 832 heterogeneous employees in China reported comparable results. Wu and Lee (2020), however, obtained a slightly divergent result, with psychological capital fully mediating the relationship between calling orientation and employee engagement.

On the basis of these findings, the authors formulated the following hypothesis:

Hypothesis 8: Calling orientation has a positive influence on employee engagement.

\section{Research design Research approach}

A quantitative research approach was used in the study to achieve its research objectives. A cross-sectional survey of EI, work locus of control, psychological capital, calling orientation and employee engagement was used to collect primary data. 


\section{Research method}

\section{Research participants}

The setting for the study was public schools in the Western Cape. The Western Cape comprises of eight education districts. These districts are the Cape Winelands, Eden and Karoo, Metro Central, Metro East, Metro North, Metro South and West Coast education districts.

Non-probability purposive sampling was used to select a sample of teachers (teachers: $N=$ approximately 1824 teachers) employed in the participating 76 public schools in the Western Cape. Three hundred fifty-three participants completed the self-administered web-based survey $(19 \%$ response rate). Table 1 offers a description of the participants' biographical characteristics.

\section{Measuring instruments}

The web-based survey, which was developed specifically for the quantitative phase of the study, was made up of two sections. The first section gathered information regarding participants' biographical characteristics. The second section comprised of valid and reliable instruments that captured the latent variables of interest. The measures utilised for the evaluation of the adapted personal resource and employee engagement model are reported in the following sections.

Genos emotional intelligence inventory: The shortened version of the Genos EI inventory (Palmer et al., 2009) was used to measure key EI competencies. This self-report measure, which consists of 14 items, assesses the seven EI competencies, namely emotional self-awareness (two items, 'I am aware of how my feelings influence the decisions I make at work'), emotional expression (two items, 'When someone upsets me at work I express how I feel effectively'), emotional awareness of others (two items, 'I understand the things that make people feel optimistic at work'), emotional reasoning (two items, 'I demonstrate to others that I have considered their feelings in decisions I make at work'),

TABLE 1: Biographical characteristics of participants.

\begin{tabular}{llcc}
\hline Category & Sub-category & Frequency & Percentage \\
\hline Gender & Female & 222 & 62.89 \\
& Male & 131 & 37.11 \\
& Missing values & 0 & 0.00 \\
Type of school & Fee school & 321 & 90.93 \\
& No-fee school & 31 & 8.78 \\
& Missing values & 1 & 0.28 \\
Education district & Cape Winelands & 71 & 20.11 \\
& Eden and Central Karoo & 73 & 20.68 \\
& Metro Central & 65 & 18.41 \\
& Metro East & 27 & 7.65 \\
& Metro North & 60 & 17.00 \\
& Metro South & 8 & 2.27 \\
& Overberg & 17 & 4.82 \\
& West Coast & 31 & 8.78 \\
& Missing values & 1 & 0.28 \\
\hline
\end{tabular}

Source: Adapted from Vermooten, N. (2018). Variance in employee engagement amongst public school teachers in the Western Cape Province: An exploratory study. Unpublished doctoral dissertation, University of Stellenbosch, Stellenbosch. emotional self-management (two items, 'I appropriately respond to colleagues who frustrate me at work'), emotional management of others (two items, 'I am effective in helping others feel positive at work') and emotional self-control (two items, 'When upset at work I still think clearly'). A five-point Likert-type scale varying from 1 (almost never) to 5 (almost always) was used to score responses. There were two reverse score items.

Palmer et al. (2009) reported that the reliability coefficient of the extended, as well as the shortened, version of the Genos EI inventory was satisfactory (>0.70). Palmer and his colleagues also showed evidence of construct validity (i.e. discriminant validity), as well as criterion validity (i.e. predictive validity and concurrent validity).

Work locus of control scale: The work locus of control scale (Spector, 1988) was used to measure work locus of control. This self-report measure, which consists of 16 items, assesses two subscales, namely internal work locus of control and external work locus of control. Only the internal work locus of control subscale ( 8 items; 'On most jobs, people can pretty much accomplish whatever they set out to accomplish') was used to assess work locus of control. A six-point Likert-type scale varying from 1 (disagree very much) to 6 (agree very much) was used to score responses. There were no reversescored items.

Spector (1988) reported that the reliability coefficients of work locus of control scale and its subscales were satisfactory $(>0.70)$ across six samples. Spector also demonstrated evidence of criterion validity (i.e. predictive validity).

Psychological capital questionnaire: The PsyCap questionnaire (Luthans et al., 2007) was used to measure psychological capital. This self-report measure, which consists of 24 items, assesses the four dimensions of psychological capital, namely optimism (six items; 'I am optimistic about what will happen to me in the future as it pertains to my work'), self-efficacy (six items; 'I feel confident representing my work area in meetings with management'), resilience (six items; 'I usually take stressful things at work in my stride') and hope (six items; 'At the present time I am energetically pursuing my goals'). The four subscales of the PsyCap questionnaire were combined in the study. The composite measurement indicator measured psychological capital amongst participants. A six-point Likert-type scale varying from 1 (strongly disagree) to 6 (strongly agree) was used to score responses. There were three reverse score items.

Luthans et al. (2007) reported that the reliability coefficients of the PsyCap questionnaire and its subscales were mostly satisfactory $(>0.70)$ across four heterogenous samples. Luthans and his colleagues also showed evidence of construct validity (i.e. discriminant validity), as well as criterion validity (i.e. predictive validity). 
Calling and vocation questionnaire: The calling and vocation questionnaire (Dik, Eldridge, Steger, \& Duffy, 2012) was used to measure calling orientation. This self-report measure, which consists of 24 items, assesses the two primary subscales, namely the presence of calling and the search of calling. Only the presence of calling primary subscale was used to assess calling orientation. The presence of calling subscale, which consists of 12 items, comprises of three subscales. These subscales are the presence of transcendence summons (four items; 'I believe that I have been called to my current line of work'), purposeful work (four items; 'My work helps me live out my life's purpose') and prosocial orientation (four items; 'Making a difference for others is the primary motivation in my career'). A four-point Likert-type scale varying from 1 (not at all true of me) to 4 (absolutely true of me) was used to score responses. There was one reverse score item.

Dik et al. (2012) reported that the reliability coefficients of the primary, as well as the secondary, subscales of the Calling and Vocation Questionnaire were satisfactory (>0.70). Dik and his colleagues also demonstrated evidence of construct validity (i.e. discriminant validity and convergent validity).

Utrecht Work Engagement Scale. The Utrecht Work Engagement Scale (UWES-9) (Schaufeli, Bakker, \& Salanova, 2006) was used to measure employee engagement. This self-report measure, which consists of nine items, assesses the three dimensions of employee engagement, namely vigour (three items; 'At my work, I feel bursting with energy'), dedication (three items; 'I am enthusiastic about my job') and absorption (three items; 'I am immersed in my work'). The three subscales of the UWES-9 were combined in the study. The composite measurement indicator measured employee engagement amongst participants. A seven-point Likert-type scale varying from 0 (never) to 6 (always) was used to score responses. There were no reverse-scored items.

Schaufeli et al. (2006) reported that the reliability coefficients of the UWES and its subscales were mostly satisfactory (> 0.70) across 10 heterogenous samples. Schaufeli and his colleagues also showed evidence of criterion validity (i.e. concurrent validity).

\section{Research procedure and ethical considerations}

Once principals had granted institutional permission, the first author sent an email with a link to the web-based survey to the principals or secretaries of participating public schools, depending on their preference. Principals or secretaries were asked to send the email to all the teachers who were employed at their school at that point in time. Teachers were given five working days (i.e. Monday through Friday) to participate in the quantitative phase. Principals or secretaries were asked to remind teachers to participate in the quantitative phase once during the 5-day period.

\section{Statistical analysis}

Several statistical techniques were used to analyse the primary data that was gathered for the study and to evaluate the proposed personal resources and employee engagement structural model, depicted in Figure 1. These techniques include item analysis to determine the reliability of latent variable scales, confirmatory factor analysis to validate the measurement model and partial least squares (PLS) structural equation modelling (SEM) to evaluate the structural model.

\section{Ethical considerations}

The researchers obtained approval from the Ethics Committee of the university where it was undertaken, as well as the Western Cape Department of Education, before the commencement of the study. Following this, the first author proceeded to apply for institutional permission from the principals of public schools. Principals, who agreed to participate in the study were asked to complete an institutional permission form and return it to the first author by email. The institutional permission form gave a detailed explanation of the study and the nature of participation (Ethical clearance number: SU-HSD-002152).

\section{Results}

\section{Testing the measurement model \\ Item analysis}

An item analysis was carried out on all the items that were included in the web-based survey.

Table 2 shows that the Cronbach's alpha for each latent variable scale was acceptable (>0.70) (Nunnally, 1978). Moreover, the average inter-item correlation for each latent variable scale was acceptable (>0.30) (Robinson, Shaver, \&

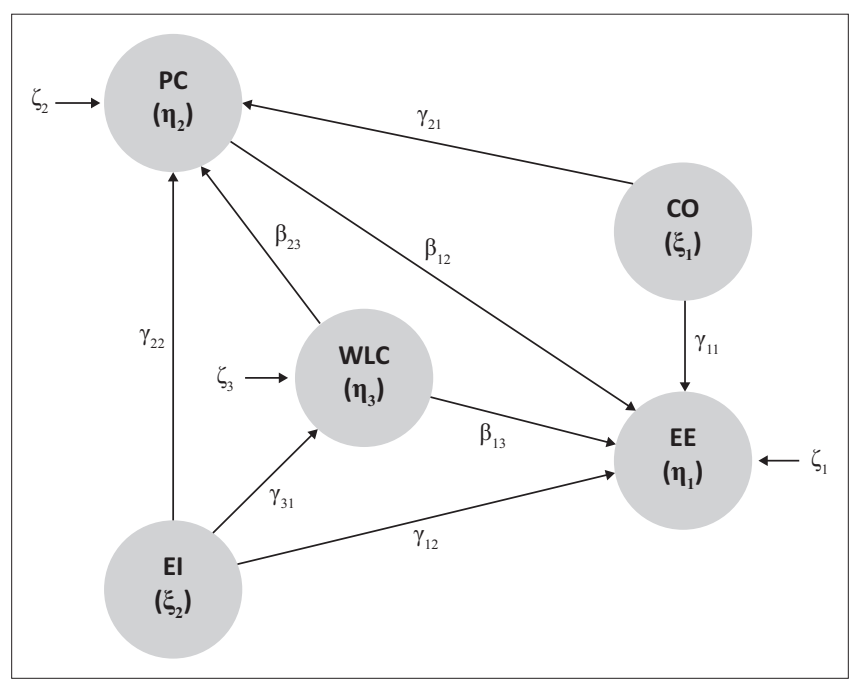

$\xi_{1}$, calling orientation; $\xi_{2}$ emotional intelligence; $\eta_{1}$, employee engagement; $\eta_{2}$, psychological capital; $\eta_{3}$, work locus of control.

WLC, work locus of control; $\mathrm{CO}$, calling orientation; El, emotional intelligence; $\mathrm{EE}$, employee engagement; PC, psychological capital.

FIGURE 1: Proposed personal resources and employee engagement structural model. 
Wrightsman, 1991), apart from the Genos EI inventory. The average inter-item correlation of the Genos EI inventory was, however, still considered 'extensive' (>0.20) (Robinson et al., 1991, p. 13).

Table 3 provides an indication of how interrelated the latent variables are.

Inspection of Table 3 shows that the different personal resources are highly correlated and that PsyCap has the strongest correlation with employee engagement.

\section{Evaluating the measurement model}

Confirmatory factor analysis was conducted to evaluate the measurement model fit. Three separate measurement models were constructed for latent variable scales that comprised of subscales. These latent variable scales are the psychological capital scale (consisting of four subscales), the calling and vocation questionnaire (consisting of three subscales) and the UWES-9 (consisting of three subscales).

Table 4 summarises the measurement models for the multidimensional measures with the statistics showing either good fit $(<0.05)$ or reasonable fit $(>0.05$ and $<0.08)$ (Hair, Black, Babin, Anderson, \& Tatham, 2006) and meeting the criteria for the goodness-of-fit index (GFI) and adjusted goodness-of-fit index (AGFI) values (> 0.90) (Hooper, Coughlan, \& Mullen, 2008). These results suggested that the measurement models mentioned above reproduced the empirical data reasonably well.

\section{Partial least squares path analysis Reliability analysis}

A reliability analysis was carried out on all the items that were included in the web-based survey.

Table 5 shows that the composite reliability $(>0.60)$ and average variance extracted (AVE) $(>0.50)$ of the latent variable scales were mostly acceptable (Hair, Ringle, \& Sarstedt, 2011). The AVE values of EI (0.27) and work locus of control (0.38) were, however, smaller than the 0.50 critical value. The AVE score refers to the amount of variance that is captured by the construct and could be seen as a measure of construct validity. Upon investigating the available evidence, the researchers concluded that the AVE values of these latent variables did not unduly influence the results obtained. The researchers, therefore, concluded that the outer-measurement model fit was acceptable. Each latent variable scale measured the construct that it was assigned to measure.

Despite the strong intercorrelations between the latent variables (Table 3), the variance inflation values (ranging from 1 to 2.208) were satisfactory $(<4.00)$ (Garson, 2016), indicating that there was no collinearity between the latent variables. In a similar vein, the heterotrait-monotrait ratios (ranging from 0.48 to 0.8$)$ were satisfactory $(<0.90)$ (Henseler, Ringle, \& Sarstedt, 2015), indicating that the latent variables displayed discriminant validity.

\section{Testing the structural model}

Table 5 shows that the $R$ square value and $R$ square adjusted value of work locus of control was moderate $(>0.19)$, whilst

TABLE 2: Cronbach's alpha, average inter-item correlation, mean and standard deviation of the measurement instruments.

\begin{tabular}{lcccc}
\hline Scale & Items & Cronbach's alpha & Inter-item correlation & Mean \\
\hline CVQ (CO) & 12 & 0.78 & 0.51 & 37.93 \\
GEII (EI) & 14 & 0.79 & 0.21 & 54.06 \\
UWES (EE) & 9 & 0.80 & 0.59 & 3.71 \\
PCQ (PC) & 24 & 0.73 & 0.33 & 6.21 \\
WLCS (WLC) & 8 & 0.76 & 0.30 & 111.75 \\
\hline
\end{tabular}

Source: Adapted from Vermooten, N. (2018). Variance in employee engagement amongst public school teachers in the Western Cape Province: An exploratory study. Unpublished doctoral dissertation, University of Stellenbosch, Stellenbosch.

CVQ, Calling and Vocation Questionnaire; CO, calling orientation; GEII, Genos Emotional Intelligence Inventory; El, emotional intelligence; UWES, Utrecht Work Engagement Scale; EE, employee engagement; PCQ, PsyCap Questionnaire; PC, psychological capital; WLCS, work locus of control scale; WLC, work locus of control.

TABLE 3: Intercorrelational matrix of the latent variables $(N=353)$

\begin{tabular}{lcccc}
\hline Variables & EI & PC & CO & WLOC \\
\hline EE & $0.50^{* *}$ & $0.71^{* *}$ & $0.61^{* *}$ & $0.47^{* *}$ \\
EI & - & $0.67^{* *}$ & $0.45^{* *}$ & $0.44^{* *}$ \\
PC & - & - & $0.51^{* *}$ \\
CO & - & - & - & $0.54^{* *}$ \\
\hline
\end{tabular}

$* * p>0.01$.

El, emotional intelligence; PC, psychological capital; CO, calling orientation; WLOC, work locus of control.

TABLE 4: Goodness-of-fit statistics of the measurement models of each multidimensional instrument.

\begin{tabular}{lcccc}
\hline Scale & S-B $\chi^{2}$ & $p$-value & RMSEA & GFI \\
\hline CVQ (CO) & 155.33 & 0.00 & 0.08 & 0.99 \\
UWES (EE) & 36.90 & 0.75 & 0.04 & 0.99 \\
PCQ (PC) & 750.85 & 0.00 & 0.08 & 1.00 \\
\hline
\end{tabular}

Source: Adapted from Vermooten, N. (2018). Variance in employee engagement amongst public school teachers in the Western Cape Province: An exploratory study. Unpublished doctoral dissertation, University of Stellenbosch, Stellenbosch.

S-B $\chi^{2}$, Satorra-Bentler chi-square; RMSEA, root mean square error of approximation; GFI, goodness-of-fit index; AGFI, adjusted goodness-of-fit index; CVQ, Calling and Vocation Questionnaire; CO, calling orientation; UWES, Utrecht Work Engagement Scale; EE, employee engagement; PCQ, PsyCap Questionnaire; PC, psychological capital. 
the $R$ square value and $R$ square adjusted value of psychological capital and employee engagement were substantial (> 0.33) (Chin, 1998). These results suggested that the structural model fit was acceptable.

Figure 2 depicts the path coefficients between the latent variables of interest. Five of the hypothesised relationships in the personal resources and employee engagement structural model were supported at the $95 \%$ confidence level. The strength of the influence of $\xi_{\mathrm{j}}$ and/or $\eta_{\mathrm{j}}$ on $\eta_{\mathrm{i}}$ was substantial and significant for the following hypotheses:

- Emotional intelligence on work locus of control $($ Path coefficient $=0.45)($ Hypothesis 2$)$

- Work locus of control on psychological capital $($ Path coefficient $=0.24)($ Hypothesis 4$)$

- Emotional intelligence on psychological capital $($ Path coefficient $=0.49)($ Hypothesis 5)

- Psychological capital on employee engagement (Path coefficient $=0.55)($ Hypothesis 6)

- Calling orientation on psychological capital (Path coefficient $=0.18)($ Hypothesis 7$)$

- Calling orientation on employee engagement (Path coefficient $=0.32)($ Hypothesis 8$)$.

Two of the hypothesised relationships between personal resources and employee engagement structural model were not supported at the $95 \%$ confidence level. The strength of

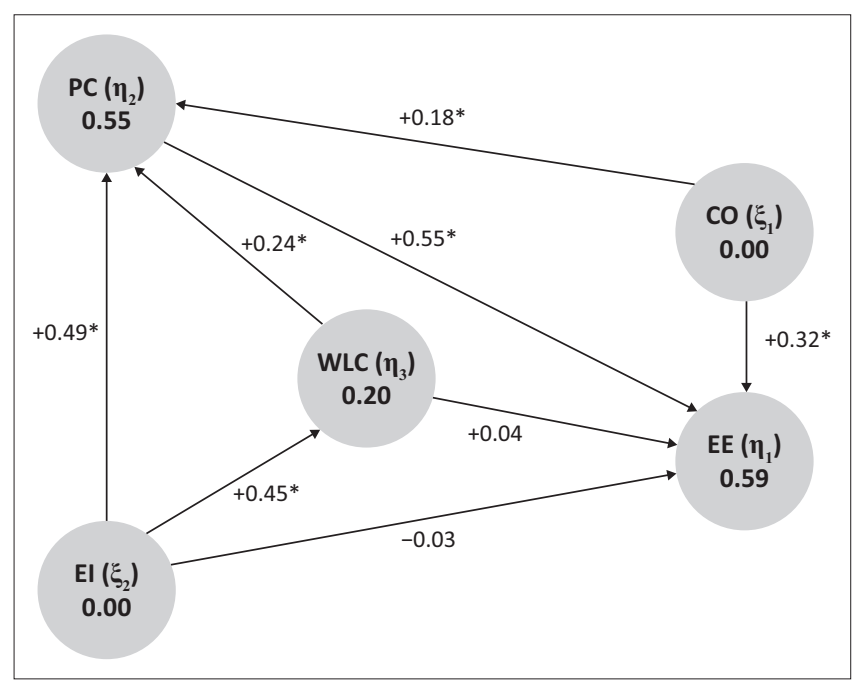

*, Significant path; $\xi_{1}$, calling orientation; $\xi_{2}$ emotional intelligence; $\eta_{1}$, employee engagement; $\eta_{2}$, psychological capital; $\eta_{3}$, work locus of control.

WLC, work locus of control; $\mathrm{CO}$, calling orientation; $\mathrm{El}$, emotional intelligence; $\mathrm{EE}$, employee engagement; PC, psychological capital.

FIGURE 2: Partial least squares report for the personal resources and employee engagement structural model. the influence of $\xi_{j}$ and/or $\eta_{j}$ on $\eta_{i}$ was not substantial or significant for the following hypotheses:

- Emotional intelligence on employee engagement (Path coefficient $=-0.03)($ Hypothesis 1$)$

- Work locus of control on employee engagement (Path coefficient $=0.04)($ Hypothesis 3).

\section{Discussion}

The researchers drew on the central tenets of the JD-R theory to examine the role of personal resources in predicting employee engagement amongst public school teachers in the Western Cape. By extrapolating from research conducted by Menguc et al. (2013), the researchers proposed that it is necessary to study the interrelatedness of the psychological resources, in order to capture the complexity of the personal resource phenomenon and its consequences for employee engagement.

A mixed-methods study conducted by Vermooten (2018) directed attention to the salience of four personal resources amongst public school teachers in the Cape Winelands. These personal resources were EI, work locus of control, psychological capital and calling orientation. For this reason, the researchers decided to explore the relational dynamics amongst EI, work locus of control, psychological capital and calling orientation and its consequences for employee engagement in the study.

\section{Outline of the results}

The results obtained from PLS SEM generally supported the hypothesised relationships. The results provided strong support for the influence of EI on work locus of control (Ng et al., 2014; Singh, 2006), EI on psychological capital (Gong et al., 2019), work locus of control on psychological capital (Shaik \& Buitendach, 2015), calling orientation on psychological capital (Wu \& Lee, 2020), psychological capital on employee engagement (Allesandri et al., 2018; Simons \& Buitendach, 2013) and calling orientation on employee engagement (Ugwu \& Nyishi, 2017; Xie et al., 2016).

Unexpectedly, the hypothesised influence of EI on employee engagement (Pérez-Fuentes et al., 2018; Turner \& Stough, 2019) and work locus of control on employee engagement (Myers, 2014) were not supported. This suggests that personal resources may not always have a direct influence on employee engagement. It was, however, clear, in accordance with the COR theory that some personal resources support other

TABLE 5: Evaluation of the partial least square inner model and outer model.

\begin{tabular}{llcc}
\hline Scale & AVE & Composite reliability & $\boldsymbol{R}^{2}$ \\
\hline CVQ (CO) & 0.72 & 0.89 & - \\
GEII (EI) & 0.27 & 0.83 & - \\
UWES (EE) & 0.82 & 0.93 & - \\
PCQ (PC) & 0.70 & 0.90 & 0.59 \\
WLCS (WLC) & 0.38 & 0.82 & 0.55 \\
\hline
\end{tabular}

AVE, average variance extracted; CVQ, calling and vocation questionnaire; CO, calling orientation; GEII, Genos Emotional Intelligence Inventory; EI, emotional intelligence; UWES, Utrecht Work Engagement Scale; EE, employee engagement; PCQ, PsyCap Questionnaire; PC, psychological capital; WLCS, work locus of control scale; WLC, work locus of control. 
personal resources. Inspection of Figure 2 reveals that psychological capital fully mediates the relationship between EI and employee engagement, as well as between work locus of control and engagement. It also serves as partial mediator between work locus of control and employee engagement, as well as between calling orientation and employee engagement. These findings strengthen the theory that 'resource caravans' (Hobfoll, 2001) are formed that have a significant positive influence on employee engagement.

The above-mentioned results captured the complexity of the personal resources phenomenon and its consequences for employee engagement. By adopting a model that explores the relational dynamics amongst personal resources, the study provided insight into the way multiple personal resources interact with one another and, in turn, foster employee engagement.

\section{Practical implications}

The study highlighted the salience of personal resources amongst public school teachers in the Western Cape. Consistent with the conservation of resources theory (Hobfoll, 1989), its results demonstrated that personal resources, specifically EI, work locus of control, psychological capital and calling orientation, generate each other and, in turn, foster employee engagement. For this reason, the researchers recommend that reasonable steps should be taken to ensure that teaching students and in-service teachers develop these personal resources. This can be achieved through career counselling, coaching and training. Teaching students can be asked to create a personal development plan that consists of specific action steps, which target personal resources that are not adequately developed. Similarly, provincial departments of education should offer coaching services that target the development of personal resources to in-service teachers.

\section{Limitations of the study and recommendations for future research}

The first limitation relates to the cross-sectional survey design that was adopted in the study. This design does not allow researchers to fully establish the causal relationships between the latent variables of interest. Longitudinal research is needed to address this limitation.

The second limitation concerns the nature of self-reported measures that were used in the study. Common method variance, associated with the use of self-reported measures, may have negatively affected the accuracy of associations between the latent variables of interest (Podsakoff, MacKenzie, Lee, \& Podsakoff, 2003). Multiple source studies are needed to address this limitation.

The third limitation relates to the underrepresentation of the no-fee paying schools in the sample, which has a negative impact on the generalisability of the results. The reasons for the low participation rates should be investigated.

\section{Concluding remarks}

The study demonstrated the importance of adopting a model that captures the complexity of the personal resources phenomenon and its consequences for employee engagement (Menguc et al., 2013). In doing so, the researchers made a meaningful contribution to the field of industrial and organisational psychology, as they were able to provide insight into the way multiple personal resources interact with one another and, in turn, foster employee engagement.

Consistent with the conservation of resources theory (Hobfoll, 1989), the results of the study demonstrated that personal resources, specifically EI, work locus of control, psychological capital and calling orientation, support each other. In turn, these personal resources foster employee engagement. In consideration of this, the researchers recommend that human resources practices should concentrate on developing personal resources to foster employee engagement.

\section{Acknowledgements}

The authors are grateful for the support received from the public schools that agreed to participate in the research study.

\section{Competing interests}

The authors declare that they have no financial or personal relationship(s) that may have inappropriately influenced them in writing this article.

\section{Authors' contribution}

N.V. conducted a review of the extant literature, facilitated the web-based survey and prepared the manuscript. J.M. and B.B. reviewed the manuscript. M.K. facilitated the data processing.

\section{Funding information}

This research received no specific grant from any funding agency in the public, commercial or not-for-profit sectors.

\section{Data availability}

New data were created and analysed in this study. Authors may be contacted in this regard.

\section{Disclaimer}

The views and opinions expressed in this article are those of the authors and do not necessarily reflect the official policy or position of any affiliated agency of the authors.

\section{References}

Allesandri, G., Consiglio, C., Luthans, F., \& Borgogni, L. (2018). Testing a dynamic model of the impact of psychological capital on work engagement and job performance. Career Development International, 23(1), 33-47. https://doi. org/10.1108/CDI-11-2016-0210 
Bailey, C., Madden, A., Alfes, K., \& Fletcher, L. (2017). The meaning, antecedents and outcomes of employee engagement: A narrative synthesis. International Journal of Management Reviews, 19(1), 31-53. https://doi.org/10.1111/ ijmr.12077

Bakker, A.B., \& Costa, P.L. (2014). Chronic job burnout and daily functioning: A theoretical analysis. Burnout Research, 1(3), 112-119. https://doi.org/10.1016/j. burn.2014.04.003

Bakker, A.B., \& Demerouti, E. (2017). Job demands-resources theory: Taking stock and looking forward. Journal of Occupational Health Psychology, 22(3), 273-285. https://doi.org/10.1037/ocp0000056

Bulmash, B. (2016). Entrepreneurial resilience: Locus of control and well-being of entrepreneurs. Journal of Entrepreneurship \& Organisation Management, 5(1) 171. https://doi.org/10.4172/2169-026X.1000171

Chin, W.W. (1998). The partial least squares approach to structural equation modeling In G.A. Marcoulides (Ed.), Modern methods for business research (pp. 295-336). Mahwah, NJ: Psychology Press.

Conway, A.M., Tugade, M.M., Catalino, L.I., \& Fredrickson, B.L. (2013). The broadenand-build theory of positive emotions: Form, function and mechanisms. In S.A. David, I. Boniwell, \& A.C. Ayers (Eds.), Oxford handbook of happiness (pp. 17-34) Oxford: Oxford University Press.

Creswell, J.W., \& Plano Clark, V.L. (2011). Designing and conducting mixed methods research (2nd ed.). Thousand Oaks, CA: Sage.

Demerouti, E., Bakker, A.B., Nachreiner, F., \& Schaufeli, W.B. (2001). The job demandsresources model of burnout. Journal of Applied Psychology, 86(3), 499-512. resources model of burnout. Journal of Applie
https://doi.org/10.1037//0021-9010.86.3.499

Dik, B.J., \& Duffy, R.D. (2009). Calling and vocation at work: Definitions and prospects for research and practice. The Counseling Psychologist, 37(3), 424-450. https:// doi.org/10.1177/0011000008316430

Dik, B.J., Eldridge, B.M., Steger, M.F., \& Duffy, R.D. (2012). Development and validation of the Calling and Vocation Questionnaire (CVQ) and Brief Calling Scale (BCS).
Journal of Career Assessment, 20(3), 242-263. https://doi.org/10.1177/ 1069072711434410

Garson, G.D. (2016). Partial least squares: Regression and structural equation models Asheboro, NC: Statistical Publishing Associates.

Gong, Z., Chen, Y., \& Wang, Y. (2019). The influence of emotional intelligence on job burnout and job performance: Mediating effect of psychological capital. Frontiers in Psychology, 10, 2707. https://doi.org/10.3389/fpsyg. 2019.02707

Hair, J.F., Black, W.C., Babin, B.J., Anderson, R.E., \& Tatham, R.L. (2006). Multivariate data analysis (6th ed.). Uppersaddle River, NJ: Pearson Prentice Hall.

Hair, J.F., Ringle, C.M., \& Sarstedt, M. (2011). PLS-SEM: Indeed a silver bullet. Journal of Marketing Theory and Practice, 19(2), 139-151. https://doi.org/10.2753/ MTP1069-6679190202

Henseler, J., Ringle, C.M., \& Sarstedt, M. (2015). A new criterion for assessing discriminant validity in variance-based structural equation modeling. Journal of the Academy of Marketing Science, 43(1), 115-135. https://doi.org/10.1007/ the Academy of Mark
s11747-014-0403-8

Hirschi, A. (2012). Callings and work engagement: Moderated mediation model of work meaningfulness, occupational identity, and occupational self-efficacy. Journal of Counseling Psychology, 59(3), 479-485. https://doi.org/10.1037/a0028949

Hobfoll, S.E. (1989). Conservation of resources: A new attempt at conceptualizing stress. American Psychologist, 44(3), 513-524. https://doi.org/10.1037/0003066X.44.3.513

Hobfoll, S.E. (2001). The influence of culture, community, and the nested-self in the stress process: Advancing conservation of resources theory. Applied Psychology, 50(3), 337-421. https://doi.org/10.1111/1464-0597.00062

Hodzic, S., Scharfen, J., Ripoll, P., Holling, H., \& Zenasni, F. (2018). How efficient are emotional intelligence trainings: A meta-analysis. Emotion Review, 10(2), 138-148. https://doi.org/10.1177/1754073917708613

Hooper, D., Coughlan, J., \& Mullen, M. (2008). Structural equation modeling: Guidelines for determining model fit. Electronic Journal of Business Research Methods, 6(1), 53-60.

Karatepe, O.M., Ozturk, A., \& Kim, T.T. (2019). The effects of nonwork and personal resources on frontline bank employees' work engagement and critical job outcomes. International Journal of Bank Marketing, 37(3), 858-879. https://doi. org/10.1108/IJBM-05-2018-0133

Kozlowski, D., Hutchinson, M., Hurley, J., \& Browne, G. (2018). Increasing nurses' emotional intelligence with a brief intervention. Applied Nursing Research, 41 59-61. https://doi.org/10.1016/j.apnr.2018.04.001

Lazarus, R.S. (1991). Progress on a cognitive-motivational-relational theory of emotion. American Psychologist, 46(8), 819-834. https://doi.org/10.1037/ 0003-066X.46.8.819

Lefcourt, H.M. (1966). Internal versus external control of reinforcement: A review. Psychological Bulletin, 65(4), 206-220. https://doi.org/10.1037/ h0023116

Lestari, S.D., \& Sawitri, D.R. (2017). Correlation between emotional intelligence and work engagement of special need school teachers. Advanced Science Letters, 23(4), 3480-3482. https://doi.org/10.1166/asl.2017.9139

Lorente, L.P., Salanova, M.S., Martínez, I.M., \& Schaufeli, W.B. (2008). Extension of the job demands-resources model in the prediction of burnout and engagement amongst teachers over time. Psicothema, 20(3), 354-360.

Luthans, F., Youssef, C.M., \& Avolio, B.J. (2007). Psychological capital: Developing the human competitive edge. Oxford: Oxford University Press. https://doi. org/10.1093/acprof:oso/9780195187526.001.0001
Mäkikangas, A., Feldt, T., Kinnunen, U., \& Mauno, S. (2013). Does personality matter? Research on individual differences in occupational well-being. In A.B. Bakker (Eds.), Advances in positive organizational psychology (Vol. 1, pp. 107-143). Bingley: Emerald Publishing.

Mayer, J.D., Salovey, P., \& Caruso, D.R. (2002). MSCEIT user's manual. Toronto: MultiHealth Systems.

Menguc, B., Auh, S., Fisher, M., \& Haddad, A. (2013). To be engaged or not to be engaged: The antecedents and consequences of service employee engagement. Journal of Business Research, 66(11), 2163-2170. https://doi.org/10.1016/j. jbusres.2012.01.007

Myers, J. (2014). Employee locus of control and engagement in nonprofit organizations (Walden dissertations and doctoral studies collection). Walden University, p. 122. Retrieved from https://scholarworks.waldenu.edu/dissertations/122

Newacheck, P.W., Rising, J.P., \& Kim, S.E. (2006). Children at risk for special health care needs. Pediatrics, 118(1), 334-342. https://doi.org/10.1542/peds.2005-2238

Ng, S.M., Ke, G.N., \& Raymond, W. (2014). The mediating role of work locus of control on the relationship among emotional intelligence, organisational citizenship behaviours, and mental health among nurses. Australian Journal of Psychology 66(4), 207-215. https://doi.org/10.1111/ajpy.12049

Northcutt, N., \& McCoy, D. (2004). Interactive qualitative analysis: A systems method for qualitative research. Thousand Oaks, CA: Sage.

Nunnally, J. (1978). Psychometric methods. New York, NY: McGraw-Hill.

Palmer, B.R., Stough, C., Harmer, R., \& Gignac, G.E. (2009). The Genos Emotional Intelligence Inventory: A measure designed specifically for workplace applications. In C. Stough, D.H. Saklofske, \& J.D. Parker (Eds.), Assessing emotional intelligence: In C. Stough, D.H. Saklofske, \& J.D. Parker (Eds.), Assessing emotional intelligence:
Theory, research, and applications (pp. 103-117). Boston, MA: Springer. https:// doi.org/10.1007/978-0-387-88370-0_6

Pérez-Fuentes, M.C., Molero, M.M., Gázquez, J.J., \& Oropesa, N.F. (2018). The role of emotional intelligence in engagement in nurses. International Journal of Environmental Research and Public Health, 15(9), 1915. https://doi:10.3390/ ijerph15091915

Petrides, K.V., Pita, R. \& Kokkinaki, F. (2007). The location of trait emotional intelligence in personality factor space. British Journal of Psychology, 98(2), 273-289. https://doi.org/10.1348/000712606X120618

Podsakoff, P.M., MacKenzie, S.B., Lee, J.Y., \& Podsakoff, N.P. (2003). Common method biases in behavioral research: A critical review of the literature and recommended remedies. Journal of Applied Psychology, 88(5), 879-903. https://doi. remedies. Journal of Applied

Richardsen, A.M. (2019). Work engagement: Increasing employee well-being and organizational effectiveness. In R.J. Burke, \& A.M. Richardsen (Eds.), Creating psychologically healthy workplaces (pp. 311-331). Cheltenham: Edward Elgar psychologicall
Publishing.

Robinson, J.P., Shaver, P.R., \& Wrightsman, L.S. (1991). Criteria for scale selection and evaluation. In J.P. Robinson, P.R. Shaver, \& L.S. Wrightsman (Eds.), Measures of personality and social psychological attitudes: Measures of social psychological personality and social psychological attitudes: Measures
attitudes (Vol. 1, pp. 1-16). New York, NY: Academic Press.

Rotter, J.B. (1966). Generalized expectancies for internal versus external control of reinforcement. Psychological Monographs: General and Applied, 80(1), 1-28. https://doi.org/10.1037/h0092976

Rotter, J.B. (1990). Internal versus external control of reinforcement: A case history of a variable. American Psychologist, 45(4), 489-493. https://doi.org/10.1037/0003066X.45.4.489

Schaufeli, W.B., \& Bakker, A.B. (2004). Job demands, job resources, and their relationship with burnout and engagement: A multi-sample study. Journal of Organizational Behavior, 25(3), 293-315. https://doi.org/10.1002/job.248

Schaufeli, W.B., Bakker, A.B., \& Salanova, M.S. (2006). The measurement of work engagement with a short questionnaire: A cross-national study. Educational and Psychological Measurement, 66(4), 701-716. https://doi.org/10.1177/ 0013164405282471

Schaufeli, W.B., Salanova, M.S., González-Romá, V.A., \& Bakker, A.B. (2002). The measurement of engagement and burnout: $A$ two sample confirmatory factor analytic approach. Journal of Happiness Studies, 3(1), 71-92. https://doi org/10.1023/A:1015630930326

Schaufeli, W.B., \& Taris, T.W. (2014). A critical review of the job demands-resources model: Implications for improving work and health. In G.F. Bauer \& O. Hämmig (Eds.) Bridging occupational, organizational and public health: A transdisciplinary approach (pp. 43-68). Dordrecht: Springer. https://doi.org/10.1007/978-94-007-5640-3_4

Shaik, Z., \& Buitendach, J.H. (2015). The relationship between work locus of control and psychological capital amongst middle managers in the recruitment industry of South Africa. South African Journal of Human Resource Management, 13(1) 1-12. https://doi.org/10.4102/sajhrm.v13i1.615

Simons, J.C., \& Buitendach, J.H. (2013). Psychological capital, work engagement and organisational commitment amongst call centre employees in South Africa. South African Journal of Industrial Psychology, 39(2), 1-12. https://doi.org/10.4102/ sajip.v39i2.1071

Singh, S.K. (2006). Social work professionals' emotional intelligence, locus of control and role efficacy: An exploratory study. South African Journal of Industria Psychology, 4(2), 39-45. https://doi.org/10.4102/sajhrm.v4i2.88

Spector, P.E. (1988). Development of the work locus of control scale. Journal of Occupational and Organizational Psychology, 61(4), 335-340. https://doi. org/10.1111/j.2044-8325.1988.tb00470.x

Tims, M., Bakker, A.B., \& Derks, D. (2013). The impact of job crafting on job demands, job resources, and well-being. Journal of Occupational Health Psychology, 18(2), 230-240. https://doi.org/10.1037/a0032141 
Toyama, H., \& Mauno, S. (2017). Associations of trait emotional intelligence with social support, work engagement, and creativity in Japanese eldercare nurses. Japanese Psychological Research, 59(1), 14-25. https://doi.org/10.1111/jpr.12139

Turner, K., \& Stough, C. (2019). Pre-service teachers and emotional intelligence: A scoping review. The Australian Educational Researcher, 47, 283-305. https://doi. org/10.1007/s13384-019-00352-0

Ugwu, F.O., \& Onyishi, I.E. (2017). Linking perceived organizational frustration to work engagement: The moderating roles of sense of calling and psychological meaningfulness. Journal of Career Assessment, 26(2), 220-239. https://doi. org/10.1177/1069072717692735

Vermooten, N. (2018). Variance in employee engagement amongst public schoo teachers in the Western Cape Province: An exploratory study. Unpublished doctoral dissertation, University of Stellenbosch, Stellenbosch.

Vermooten, N., Malan, D.J., \& Boonzaier, B. (2020). Variance in employee engagement A qualitative analysis among public school teachers in the Cape Winelands education district. SA Journal of Industrial Psychology, 46, a1568. https://doi. org/10.4102/sajip.v46i0.1568
Wang, Q., Bowling, N.A., \& Eschleman, K.J. (2010). A meta-analytic examination of work and general locus of control. Journal of Applied Psychology, 95(4), 761-768. https://doi.org/10.1037/a0017707

Wrzesniewski, A., McCauley, C., Rozin, P., \& Schwartz, B. (1997). Jobs, careers, and callings: People's relations to their work. Journal of Research in Personality, 31(1), 21-33. https://doi.org/10.1006/jrpe.1997.2162

Wu, W., \& Lee, Y. (2020). How spiritual leadership boosts nurses' work engagement: The mediating roles of calling and psychological capital. International Journal of Environmental Research and Public Health, 17(17), 6364. https://doi.org/10.3390/ ijerph17176364

Xanthopoulou, D., Bakker, A.B., Demerouti, E., \& Schaufeli, W.B. (2007). The role of personal resources in the job demands-resources model. International Journal of Stress Management, 14(2), 121-141. https://doi.org/10.1037/1072-5245.14.2.121

Xie, B., Xia, M., Xin, X., \& Zhou, W. (2016). Linking calling to work engagement and subjective career success: The perspective of career construction theory. Journal of Vocational Behavior, 94, 70-78. https://doi.org/10.1016/j. jvb.2016.02.011 